\title{
Successful Left Atrial Appendage Closure with Watchman Device Implantation in Two Patients with Inferior Vena Cava Filters
}

\author{
Fabricio Vassallo ${ }^{1,2, *}$, Luciano Santos ${ }^{3}$, Betina Reseck Walker ${ }^{1,2}$, Rodrigo França1,2, Christina \\ Madeira ${ }^{1,2}$, Vinícius Mauro ${ }^{1,2}$, Felipe César ${ }^{1,2}$, Lucas Corcino ${ }^{2}$, Renato Serpa ${ }^{1,2}$
}

\section{ORCID ID}

Vassallo F (D) https://orcid.org/0000-0003-3915-4309

\begin{abstract}
Percutaneous procedures through femoral access in patients with inferior vena cava (IVC) filter may be at risk of complications. We evaluated the feasibility and safety of left atrial appendage closure (LAAC) through femoral access in patients previously implanted with IVC filter. We described the Watchman ${ }^{\text {TM }}$ device implantation in two patients with formal contraindication for oral anticoagulation. First patient had a Greenfield ${ }^{\mathrm{TM}}$ filter and the second one an Optease ${ }^{\mathrm{TM}}$ filter, and in this patient an attempt to withdrawal the filter immediately before the LAAC procedure failed. A femoral approach was performed in both patients using a 14 Fr sheath. Before crossing IVC filters, venographies did not detect any thrombus. All steps of IVC filter crossing were performed under fluoroscopic guidance. No immediate or intrahospital complications related to the procedure occurred. Herein, we presented two cases of successful LAAC closure with Watchman device in patients with two different kinds of IVC filters.
\end{abstract}

KEYWORDS: Atrial fibrillation; Oral anticoagulation contraindication; Left atrial appendage closure; Percutaneous intervention; Vena cava filters.

\section{INTRODUCTION}

An increasing number of percutaneous cardiac interventions for structural heart diseases is described worldwide, and these interventions concern a growing population. Among these procedures, left atrial appendage closure (LAAC) is recommended by guidelines in patients with non-valvular atrial fibrillation (AF) at high risk of thromboembolism and contraindicated for long-term oral anticoagulation (OAC $)^{1,2}$. In the setting of OAC contraindication, the implantation of inferior vena cava (IVC) filter is recommended in patients who experienced

1. Instituto de Cardiologia do Espírito Santo - Vitória (ES), Brazil.

2. Hospital Santa Rita Cássia - Vitória (ES), Brazil.

3. Hospital Santa Lúcia - Brasília (DF), Brazil.

*Corresponding author: fabricio@arritmiaes.org

Received: May 8, 2021 | Accepted: Jul 21, 2021 
venous thromboembolism (VTE) event, and as these patients also may have atrial fibrillation (AF) they would be eligible for LAAC. However, LAAC requires venous transfemoral approach to access the left atrium by transeptal puncture, which is usually considered to be contraindicated in IVC filter cases due to the risks of guidewire entrapment and filter dislodgment ${ }^{3-5}$. Simultaneously, several reports ${ }^{6-9}$ have shown the feasibility and safety of crossing an IVC filter using large sheaths up to $21 \mathrm{Fr}$, allowing various interventional procedures in the right atrium, on the atrial septum, or requiring transseptal puncture. In this manuscript, we addressed the feasibility of two Watchman devices implantation in patients across a previously implanted IVC filter.

\section{CASES PRESENTATION}

The first subject was an 82-year-old male with multiple urinary tract bleeding due to OAC for thromboembolic events prevention associated to a permanent AF. This bleeding was responsible for clinical symptoms of fatigue, tiredness, dyspnea, an important physical limitation that required hospital admission. The cause of the bleedings was secondary to an actinic cystitis after radiotherapy for a vesical cancer. In this admission, patient presented hemoglobin level of $4.8 \mathrm{~g} / \mathrm{dL}$ with the use of Rivaroxaban for a left iliac vein thrombosis with important clinical aspects. At this time, the OAC was interrupted, and the vascular team implanted a Greenfield (Boston Scientific) IVC filter (Fig. 1). Later, the patient was referred to the electrophysiology section for an evaluation to perform a LAAC. In April 2021, we performed a 27-mm Watchman (Fig. 2) implantation with no further complications.

The second subject was an 81-year-old female with $\mathrm{OAC}$ symptomatic $\mathrm{AF}$ associated with previous ischemic strokes in July and November 2020 with posterior prescription of Edoxaban. In January 2021, the patient was admitted after a massive digestive hemorrhage with hemodynamic instability and need of transfusions. After a normal superior endoscopy, a colonoscopy showed signals of an angiodysplasia of the entire colon with active bleedings associated with diverticular colonic disease. After hospital discharge, the patient was referred to LAAC, which was performed in April 2021 with a Watchman device number 33 (Fig. 3). This patient had a previous Optease (Cordis) IVC filter (Fig. 4), due to a previous femoral vein thrombosis.

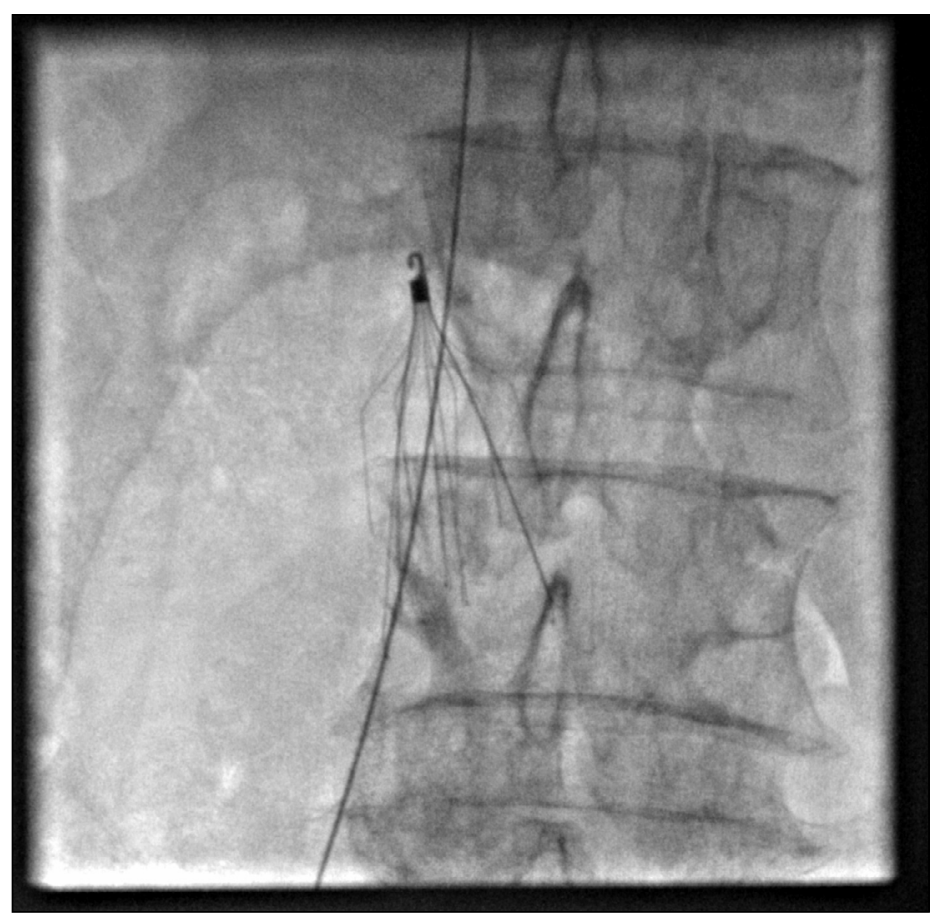

Figure 1. Greenfield inferior vena cava filter and J shape guidewire 0.035 passing through it. 


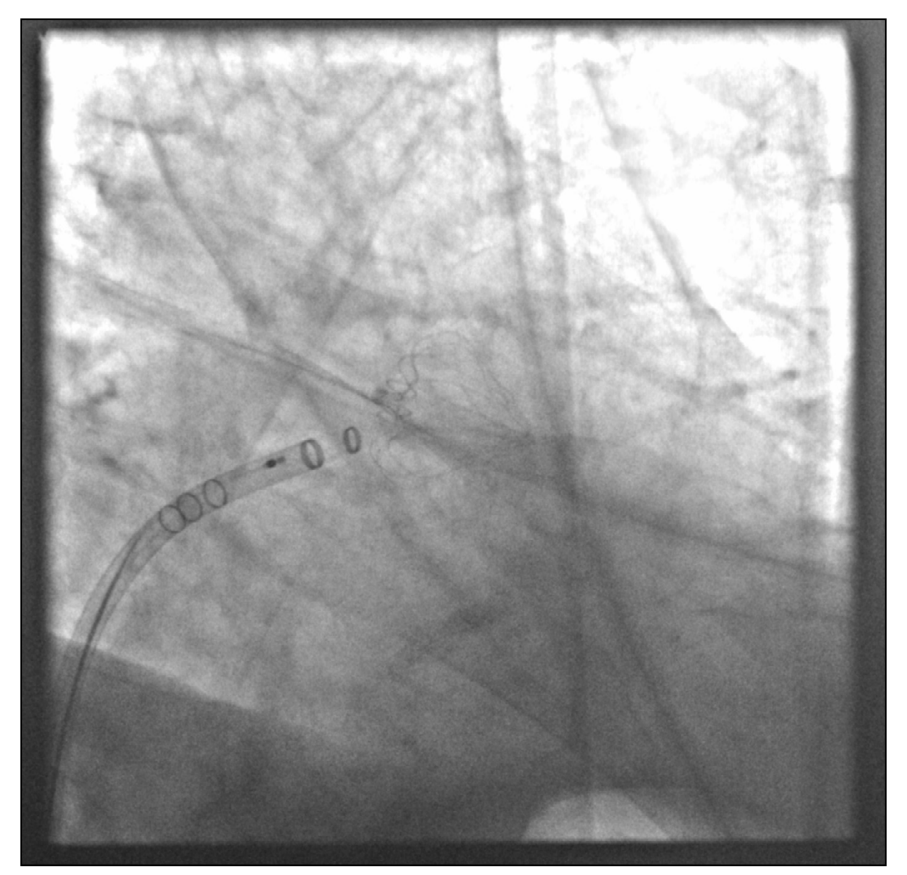

Figure 2. Final position of Watchman device number $27 \mathrm{~mm}$ in left atrial appendage.

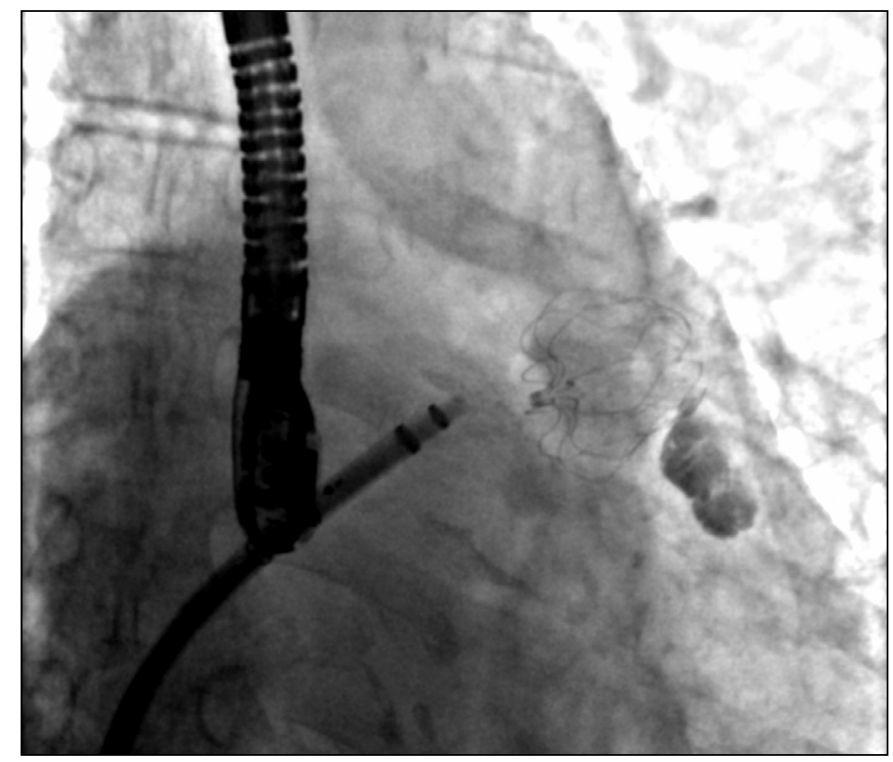

Figure 3. Final position of Watchman device number $33 \mathrm{~mm}$ in left atrial appendage.

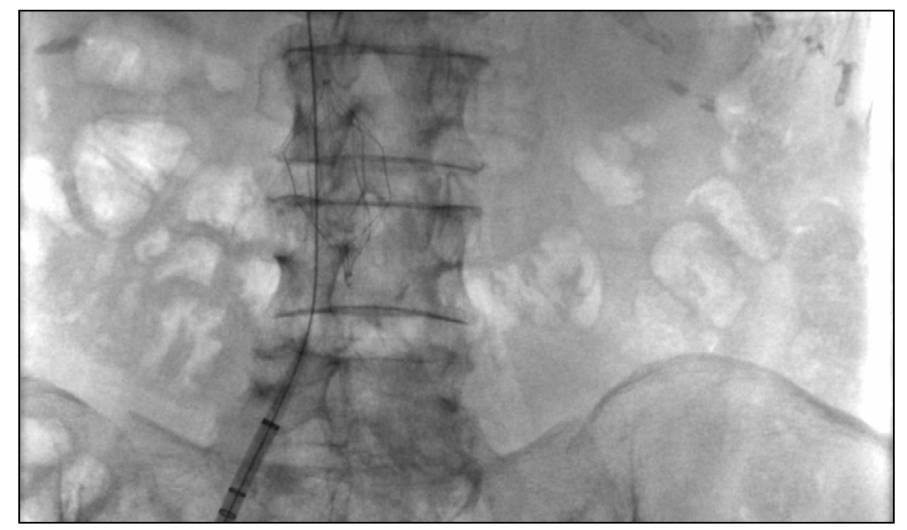

Figure 4. Optease inferior vena cava filter and J shape guidewire 0.035 passing through it. 


\section{LEFT ATRIAL APPENDAGE CLOSURE PROCEDURES}

All procedures were performed under general anesthesia with transesophageal echocardiogram (TEE) monitoring for accurate device positioning and safety. A right femoral venous access was achieved in all patients using $8 \mathrm{Fr}$ introducers. Before crossing the IVC filter, a venography was performed with nonionic contrast media dye for detection of filter or IVC thrombosis, and the IVC filter position was stored on fluoroscopy for posterior confirmation and detection of possible device migration. A .035" stiff J-tipped guidewire (Abbott) was advanced into the superior vena cava (SVC) under fluoroscopic guidance across the IVC filter, avoiding the center of the filter preferably by the right side of the IVC (Fig. 5) to have a better angle with a posteroinferior access during the interatrial septum puncture. A 63-cm long-sheath Swartz SL1 braided transseptal guiding introducer (Abbott) and a dilator were inserted through the IVC filter into the SVC over the guidewire. Then, a posteroinferior transseptal puncture was performed using a 71-cm BRK transseptal needle (Abbott), and a .035" guidewire was positioned into the left upper pulmonary vein. After that, a 14Fr delivery sheath (Boston Scientific) was advanced under fluoroscopy guidance through the left atrium, and then, a 6Fr regular pigtail was advanced into the LAAC in order to safely position the delivery sheath deeper into the LAAC. Watchman device (Boston Scientific) was appropriately sized and positioned, by TEE and fluoroscopy, at the LAAC landing zone. Before device release, we followed the recommended "position, anchor, size, and seal", the PASS acronym criteria for the Watchman device.

In the second patient the procedure was performed immediately after a failure attempt of filter withdrawal by the vascular team. After the procedure, patients were admitted for 24 hours and had a transthoracic echocardiography evaluation the following day.

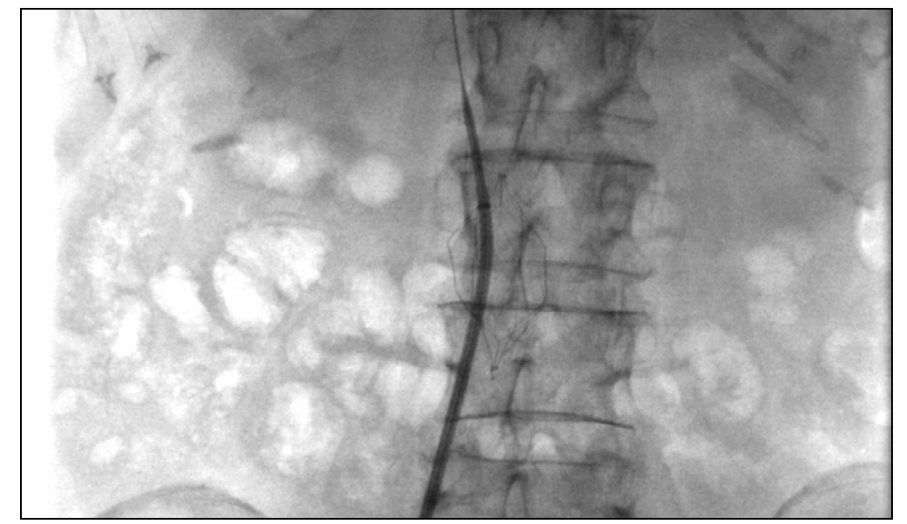

Figure 5. Right side lateral guidance of J-shaped guidewire, avoiding the center of the inferior vena cava filter.

\section{DISCUSSION}

Several reports have shown the feasibility and safety of transcatheter interventions with large sheaths through a previously implanted IVC filter ${ }^{6-9}$. In our personal experience this were the first patients requiring LAAC with previous implanted IVC filters. AF patients indicated for LAAC have a high thromboembolic risk normally associated with a contraindication to long-term OAC. In the same way, IVC filter implantation is required in patients with a VTE event in case of OAC contraindication, and both AF and VTE have common risk factors, as previously demonstrated ${ }^{10,11}$. Therefore, performing LAAC using the femoral approach in patients with a previously implanted IVC filter is not uncommon, and the access through an IVC filter can carry some risks.

Cases of guidewire entrapment and filter dislodgment, as well as the theoretical risk of pulmonary embolism related to clot embolism from the IVC filter, have been reported. Guidewire entrapment by some old IVC filters can occur, particularly with J-tipped guidewires, and it is conceivable that some filters are more likely to entrap catheters or to be dislodged than others. Two in-vitro studies reported by Kaufman et al. ${ }^{3}$ and Stavropoulos et al. ${ }^{5}$ evaluated, respectively, six and eight commercially available IVC filters in the United States and four standard guidewire shapes (15 mm, $3 \mathrm{~mm}$, and $1.5 \mathrm{~mm}$ J-tipped, and straight) in an artificial vein. The aim of these studies was to compare the risk of engaging and 
entrapping guidewires in the IVC filters. They found that the TrapEase ${ }^{\mathrm{TM}}$, the $12 \mathrm{Fr}$ stainless-steel Greenfield ${ }^{\mathrm{TM}}$ device, and the VenaTech LGM ${ }^{\mathrm{TM}}$ device could entrap guidewires with a J-tip $3 \mathrm{~mm}$ or less.

In the series by $\mathrm{El}$ Ayech et al. ${ }^{12}$ of LAAC using Amulet and Watchman devices, IVC filter devices were performed via transfemoral approach in patients with previously implanted ALN ${ }^{\mathrm{TM}}$ IVC Filter (ALN Implants Chirurgicaux) and VenaTech LP (B. Braun) using J-tipped guidewires. All procedures were successfully performed without IVC filter-related complications despite repeated crossing through the IVC filter by J-tipped guidewires, the transseptal puncture systems, and the dedicated delivery sheaths.

Of note, LAAC was performed at least two months after IVC filter implantation, which is the time limit for device reendothelialization in our second procedure and different from our first case, when we performed the LAAC 10 days after IVC implantation. Therefore, we think that this procedure is safe as long as careful manipulation of guidewires and sheaths under x-ray guidance and venography are performed, if necessary. In case of wire entrapment, its early identification and the use of an appropriate technique under fluoroscopic guidance are associated with a high success rate of disengagement, avoiding filter dislodgment. Okutucu et al. ${ }^{13}$ described a case with iliac vein and IVC thrombosis that was referred for a Watchman implantation due to permanent $\mathrm{AF}$ and the impossibility to use OAC. In their case, the thrombosis was passed by a hydrophilic coated angled glide guidewire with successful Watchman implantation.

Besides femoral venous approach for LAAC is the mainstay, nowadays several alternatives could be used especially when IVC filter thrombosis or obstruction are present. Transjugular, upper-extremity, and transhepatic venous approaches were previously reported in patent foramen interventional procedures ${ }^{14-16}$. However, these techniques are more difficult than the usual femoral access since the equipment used was designed primarily for manipulation from the lower extremities.

\section{CONCLUSION}

These two cases here described confirm the safety and efficacy of LAAC with Watchman device across a previously implanted IVC filter. Careful approach under fluoroscopic guidance and venography should be used to avoid complications such as filters dislodgements.

\section{AUTHOR'S CONTRIBUTION}

All authors contributed equally to the study, except the corresponding author, that collected the data and wrote it.

\section{DATA AVAILABILITY STATEMENT}

Data will be available upon request

\section{FUNDING}

This study has no financial support source.

\section{ACKNOWLEDGMENTS}

We thank the nurse staff team Elaine Bernardes, Shirley Tessinari, Valesca Paixão, for their effort and dedication on this case. 


\section{CONFLICT OF INTERESTS}

Fabricio Vassallo, Christiano Cunha, Eduardo Serpa, Aloyr Simões Jr. and Hermes Carloni certify that they have no affiliations with or involvement in any organization or entity with any financial interest (such as honoraria; educational grants; participation in speakers' bureaus; membership, employment, consultancies, stock ownership, or other equity interest; and expert testimony or patent-licensing arrangements), or non-financial interest (such as personal or professional relationships, affiliations, knowledge or beliefs) in the subject matter or materials discussed in this manuscript. Edevaldo da Silva is an employee of Abbott Brazil, an organization with a financial or non-financial interest in the subject matter or materials discussed in this manuscript. Fabricio Vassallo received honorarium from Boston Scientific as a proctor for Watchman device implantations.

\section{REFERENCES}

1. Magalhães LP, Figueiredo MJO, Cintra FD, Saad EB, Kuniyoshi RR, Teixeira RA, et al. II Diretrizes Brasileiras de Fibrilação Atrial. Arq Bras Cardiol. 2016;106(4 Suppl. 2):1-22.

2. 2020 ESC Guidelines for the diagnosis and management of atrial fibrillation developed in collaboration with the European Association of Cardio-Thoracic Surgery (EACTS). Eur Heart J. 2021;42(5):546-7. https://doi.org/10.1093/eurheartj/ehaa945

3. Kaufman JA, Thomas JW, Geller SC, Rivitz SM, Waltman AC. Guide-wire entrapment by inferior vena caval filters: in vitro evaluation. Radiology. 1996;198(1):71-6. https://doi.org/10.1148/radiology.198.1.8539409

4. Andrews RT, Geschwind JF, Savader SJ, Venbrux AC. Entrapment of J-tip guidewires by Venatech and stainless-steel Greenfield vena cava filters during central venous catheter placement: percutaneous management in four patients. Cardiovasc Intervent Radiol. 1998;21(5):424-8. https://doi.org/10.1007/s002709900292

5. Stavropoulos SW, Itkin M, Trerotola SO. In vitro study of guide wire entrapment in currently available inferior vena cava filters. J Vasc Interv Radiol. 2003;14(7):905-10. https://doi.org/10.1097/01.rvi.0000082827.75926.10

6. Haman L, Parizek P, Maly R, Vojacek J. Cavotricuspid isthmus catheter ablation across an inferior vena cava filter. Pacing Clin Electrophysiol. 2006;29(3):331-3. https://doi.org/10.1111/j.1540-8159.2006.00343.x

7. Jez J, Starek Z, Lehar F, Wolf J, Novak M. Complex electrophysiology intervention in a patient with an inferior vena cava filter. Cor Vasa. 2015;57(5):e341-6. https://doi.org/10.1016/j.crvasa.2015.05.005

8. Schoeffler M, Ringewald J, Schechter E. Transfemoral venous access through inferior vena cava filters for interventions requiring large sheaths. Catheter Cardiovasc Interv. 2007;69(1):47-51. https://doi.org/10.1002/ccd.20933

9. Sinha SK, Harnick D, Gomes JA, Mehta D. Electrophysiologic interventions in patients with inferior vena cava filters: safety and efficacy of the transfemoral approach. Heart Rhythm. 2005;2(1):15-8. https://doi.org/10.1016/j.hrthm.2004.09.026

10. Shariff N, Aleem A, Singh M, Li Y, Smith S. AF and venous thromboembolism- pathophysiology, risk assessment and CHADS-VASC score. J Atr Fibrillation. 2012;5(3):649. https://doi.org/10.4022/jafib.649

11. Enga KF, Rye-Holmboe I, Hald EM, Lochen M-L, Mathiesen EB, Njolstad I, et al. Atrial fibrillation and future risk of venous thromboembolism:the Troms. study. J Thromb Haemost. 2015;13(1):10-6. https://doi.org/10.1111/jth.12762

12. El Ayech F, Ternacle J, Boudiche S, Gallet R, Boukantar M, Hamon D, et al. Percutaneous left atrial appendage closure in patients with inferior vena cava filters: a case series. J Invasive Cardiol. 2019;31(5):128-32.

13. Okutucu S, Ates I, Marmagkiolis K, Kose G, Iliescu C, Cilingiroglu M. Successful Watchman device implantation in a patient with IVC filter thrombosis and iliac vein occlusions. Cardiovasc Revasc Med. 2020;21(3):409-11. https://doi.org/10.1016/j.carrev.2019.05.028

14. Sader MA, De Moor M, Pomerantsev E, Palacios IF. Percutaneous transcatheter patent foramen ovale closure using the right internal jugular venous approach. Catheter Cardiovasc Interv. 2003;60(4):536-9. https://doi.org/10.1002/ccd.10702

15. Lim HE, Pak H-N, Tse H-F, Lau C-P, Hwang C, Kim Y-H. Catheter ablation of atrial fibrillation via superior approach in patients with interruption of the inferior vena cava. Heart Rhythm. 2009;6(2):174-9. https://doi.org/10.1016/j.hrthm.2008.10.026 
16. Hussain J, Strumpf R, Ghandforoush A, Jamal A, Diethrich E. Transhepatic approach to closure of patent foramen ovale: report of 2 cases in adults. Tex Heart Inst J. 2010;37(5):553-6. http://www.ncbi.nlm. nih.gov/pmc/articles/pmc2953222/

17. Johnson JL, Fellows KE, Murphy JD. Transhepatic central venous access for cardiac catheterization and radiologic intervention. Cathet Cardiovasc Diagn. 1995;35(2):168-71. https://doi.org/10.1002/ccd.1810350219 